Revista Mídia e Cotidiano

Artigo Seção Livre

Volume 11, Número 1, abril de 2017

Submetido em: 17/03/2017

Aprovado em: 28/04/2017

\title{
DIREITOS HUMANOS E COTIDIANO: uma visada empírica
}

\section{HUMAN RIGHTS AND EVERYDAY LIFE: an empirical view}

\author{
José Ricardo CUNHA ${ }^{1}$
}

Resumo: $O$ artigo tem como referência teórica os conceitos de redistribuição e reconhecimento, decisivos no debate da filosofia moral e filosofia política contemporâneas. Utilizo esses conceitos como instrumento de análise de parte dos resultados de uma pesquisa feita pelo Grupo de Pesquisa Direitos Humanos, Poder Judiciário e Sociedade, vinculado ao Programa de Pós-Graduação em Direito da UERJ. Trata-se de uma pesquisa por amostra estratificada, realizada com a população da cidade do Rio de Janeiro, na qual a população da cidade respondeu certas perguntas sobre questões do cotidiano da cidade que envolve temas de direitos humanos. A articulação entre direitos humanos e cotidiano considerou o cotidiano não como aquilo que é comum ou banal, mas sim como uma certa maneira de ver o mundo e se relacionar com ele, onde vivências e percepções revelam o modo se ser e de pensar de um grupo.

Palavras-chave: Direitos Humanos; Redistribuição; Reconhecimento; População do Rio de Janeiro.

Abstract: This article draws from the concepts of redistribution and recognition, decisive in the debates about contemporary moral philosophy and political philosophy. It uses these concepts as instruments for analyzing part of the results of a research carried out by the Human Rights, Judiciary and Society Research Group, linked to the UERJ's Graduate Program in Law. This is a stratified sample survey conducted with the population of the city of Rio de Janeiro, in which the population of the city answered certain questions about daily life in the city that involve human rights issues. The articulation between human rights and daily life did not consider the everyday as something common or banal. Rather, it considered it as a certain way of seeing the world and relating to it, where experiences and perceptions reveal a group's way of being and thinking.

Keywords: Human rights; Redistribution; Recognition; Population of Rio de Janeiro.

\footnotetext{
1 José Ricardo Cunha é Professor Associado da Faculdade de Direito da Universidade do Estado do Rio de Janeiro. Doutor em Filosofia do Direito pela UFSC e mestre em Teoria do Estado e Direito Constitucional pela PUC-Rio. Graduado em Direito pela UFRJ. Coordena o Grupo de Pesquisa Direitos Humanos, Poder Judiciário e Sociedade da UERJ. E-mail: jr-cunha@uol.com.br.
} 
Introdução

Os direitos humanos não são apenas uma prática institucional, de natureza política e jurídica. Eles revelam, também, uma certa forma de ver o mundo; expressam um conjunto de valores de um determinado grupo social e, nesse sentido, manifestam a maneira pela qual esse grupo se relaciona com as demais pessoas nas suas interações sociais. O caráter diversificado das questões de direitos humanos faz com que eles se apresentem como questões do dia a dia. Claro que há grandes problemas que desafiam os direitos humanos, especialmente no que diz respeito às práticas institucionais, porém existem pequenas questões que se apresentam em inúmeras situações do cotidiano e que estão diretamente conectadas aos direitos humanos. Isso significa tomar tais direitos como crenças morais profundas das pessoas acerca daquilo que elas entendem como certo ou errado, como justo ou injusto e que estão presentes no dia a dia de nossa vida normal. Estamos andando na rua e nos deparamos com um indigente. Que tipo de sentimento moral isso nos desperta? Achamos que é justo ou injusto uma pessoa estar naquela situação? Lendo o jornal nos deparamos com a notícia de uma agressão cometida por um policial contra um suspeito. Achamos isso certo ou errado? São situações do dia a dia que invocam crenças que no mundo contemporâneo costumam ser mediadas pelo que chamamos de direitos humanos.

O presente artigo analisa e coloca em destaque alguns aspectos da percepção que a população do Rio de Janeiro possui sobre os direitos humanos a partir de situações que ocorrem no cotidiano da vida da cidade. A análise parte dos dados produzidos a partir da pesquisa denominada "Investigando Convicções Morais: o que pensa a população do Rio de Janeiro sobre os direitos humanos", realizada pelo Grupo de Pesquisa DHPJS. ${ }^{2}$ A pesquisa, realizada em 2015, investigou a percepção que a população do Rio de Janeiro possui sobre os direitos humanos. Para que fique claro ao nosso leitor os fundamentos técnicos da pesquisa, passo para uma necessária explicação metodológica.

A população pesquisada compreendeu moradores da cidade do Rio de Janeiro com 16 anos de idade ou mais, identificados como tal por meio de autodeclaração de idade e

\footnotetext{
2 Grupo de Pesquisa Direitos Humanos, Poder Judiciário e Sociedade, vinculado ao Programa de Pós-Graduação em Direito da Faculdade de Direito da UERJ.
} 
bairro de residência. Foi utilizada amostragem por cotas proporcionais de sexo, cor/raça e nível de instrução, dentro de sete áreas de pesquisa formadas a partir da agregação de Regiões Administrativas da cidade do Rio de Janeiro. Esse tipo de amostragem foi escolhido considerando que produz resultados similares aos obtidos com o uso de amostragem probabilística quando investigadas questões relacionadas à opinião e comportamento. O tamanho da amostra foi definido considerando o nível de precisão desejado para as estimativas dos indicadores selecionados, ou seja, para proporções de pessoas com determinadas categorias. Embora o plano amostral proposto para o levantamento tenha sido equivalente à amostragem estratificada, no cálculo dos valores esperados da precisão das estimativas, foram utilizados os procedimentos referentes a um plano de amostragem aleatória simples. Tal decisão foi motivada pela simplicidade de sua aplicação e pelo fato de que, ao aplicar um plano estratificado simples, pode-se obter algum ganho de precisão das estimativas em relação àquelas obtidas sob amostragem aleatória simples. A fórmula utilizada no cálculo do tamanho da amostra é a seguinte: $\mathrm{N}$ é o tamanho da amostra; $\mathrm{t}$ é a abscissa da curva normal para o risco $\alpha$; P é o valor da proporção que se quer estimar através da amostra; d é a precisão ou erro máximo provável; e $\alpha$ é o risco de cometer um erro maior ou igual a d ao usar p para estimar P. Considerando que o valor do erro aumenta quando a proporção se aproxima de $50 \%$, foi adotado o seu maior valor possível, ou seja, $\mathrm{P}=0.5$. Nos casos em que a proporção a ser estimada foi inferior ou superior a 50\%, o erro é menor. Foi adotado um nível de confiança de $95 \%$ para um erro absoluto máximo de 5\%. Sendo assim, o tamanho inicial da amostra foi calculado em 384 pessoas. A alocação da amostra total de pessoas em cada cota foi proporcional ao número total de pessoas com as características levadas em consideração no momento do desenho das cotas. Os totais utilizados no cálculo das proporções na população foram os apresentados pelo Censo 2010 do IBGE. Em razão de arredondamento feito, a amostra final ficou com 388 pessoas.

O questionário foi desenhado pelos pesquisadores do Grupo de Pesquisas Diretos Humanos, Poder Judiciário e Sociedade e pré-testes foram conduzidos com respondentes não especialistas, com perfil socioeconômico da população de estudo. Ele foi dividido em nove blocos de perguntas, com um total de 37 perguntas fechadas, com respostas de 
múltipla escolha, incluindo escala de valores do tipo Likert e atribuição de notas. No primeiro bloco, foi investigado se os respondentes consideravam situações especificadas como questões que deveriam ser garantidas como direitos humanos. O segundo bloco tratou de questões que os respondentes consideram violação de direitos humanos. Nos dois blocos seguintes, os respondentes apontaram, dentre as instituições apresentadas, aquelas que mais violam e as que mais protegem os direitos humanos. No quinto bloco, os respondentes manifestaram o grau de concordância/discordância em relação a expressões comumente encontradas em discursos populares. No oitavo bloco, o respondente selecionou as três áreas, dentre as apresentadas, que considera prioritária para o investimento de recursos públicos. No último bloco, o entrevistado atribuiu nota de zero a 10 às instituições mencionadas. Para o presente artigo, selecionei apenas algumas questões especificamente pertinentes ao cotidiano da cidade.

\section{Analisando os dados}

Como é sabido, a perspectiva acadêmica da compreensão dos direitos humanos construiu uma teoria geral que agrupa esses direitos em duas grandes dimensões: os direitos civis e políticos (primeira dimensão) e os direitos econômicos e sociais (segunda dimensão). ${ }^{3}$ Enquanto os que estão na primeira dimensão correspondem aos direitos mais elementares da vida política (direito à manutenção da vida, à segurança e integridade e a todas as liberdades positivas e negativas), os direitos que estão na segunda dimensão correspondem àqueles que qualificam o sujeito para a vida social (direito à saúde, educação, trabalho e renda, previdência etc.). Ao mesmo tempo em que os primeiros estão, sem dúvida, inspirados pelo valor da liberdade, os segundos estão orientados pelo valor da igualdade. De alguma forma, essa mesma perspectiva reaparece na literatura da teoria política contemporânea por meio do debate entre os defensores das políticas de redistribuição e dos defensores das políticas de reconhecimento. Enquanto os primeiros argumentam que as contradições econômicas estão no coração dos conflitos sociais modernos, isto é, são um problema de igualdade de oportunidades e de pleno acesso a bens e serviços essenciais, os segundos argumentam que são as contradições culturais que

\footnotetext{
${ }^{3}$ Não cabe nos limites desse artigo entrar no debate acerca das demais dimensões $\left(3^{\mathrm{a}}, 4^{\mathrm{a}}\right.$ etc...).
} 
estão no coração dos conflitos sociais modernos, isto é, um problema de exercício pleno e autônomo da liberdade e do direito à diferença. (FRASER; HONNETH, 2003).

Tanto a classificação dos direitos humanos em civis e politicos e econômicos e sociais, quanto as categorias de redistribuição e reconhecimento são importantes chaves de leitura que ajudam na melhor compreensão dos conflitos sociais e na luta pela constituição de uma sociedade de pessoas livres e iguais. A literatura especializada é farta nesse sentido. Entretanto, o que raramente acontece é a articulação destas categorias (ou chaves de leitura, como denominei acima) com a realidade empiricamente compreendida, sobretudo quando se busca a ideia que as pessoas possuem acerca dos direitos humanos como convicções morais ou categorias existenciais.

Tabela 1: Você acha que as situações abaixo devem ser garantidas como direitos humanos?

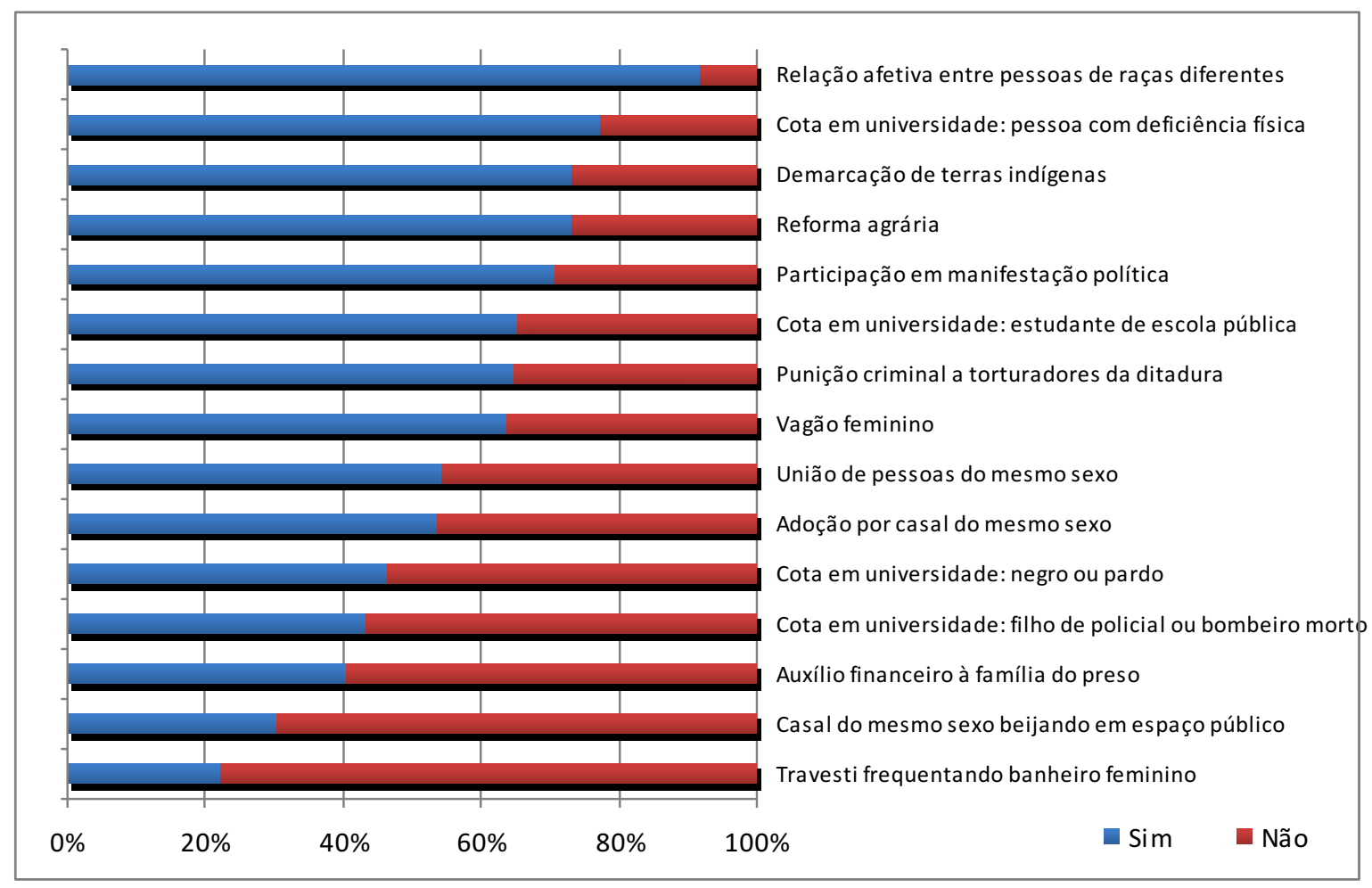

As opções apontadas pela pesquisa giram, majoritariamente, em torno de situações que poderiam ser classificadas como direitos civis e políticos e dentro dos parâmetros das lutas por reconhecimentos. Chama à atenção as respostas que apareceram nas posições 
polares: $92 \%$ dos respondentes consideram que relações afetivas entre pessoas de raça diferente caracterizam uma situação que deve ser garantida como sendo um direito humano. Por outro lado, 70\% dos entrevistados consideraram que o beijo em espaço público de casais do mesmo sexo não deve ser garantido como um direito humano. Se, por um lado, a população do Rio parece ter constituído a convicção de que é moralmente errado levantar barreiras raciais no relacionamento entre as pessoas, por outro lado ainda há muita resistência às relações homoafetivas. Ora, desde a abolição da escravatura no Brasil a luta por reconhecimento dos grupos afrodescendentes sempre foi árdua e intensa, sem pausa para tréguas. Embora ainda haja muito preconceito racial difundido na sociedade brasileira, há, também, muitos avanços não apenas nos planos legal e institucional, mas, também, na conformação da consciência moral dos indivíduos. Esse mesmo caminho ainda não foi totalmente trilhado quando se fala em garantia de direitos de grupos LGBT. A pesquisa mostra o quanto ainda falta trilhar nessa área para a formação de uma sociedade de pessoas livres e iguais, com respeito à diferença e a diversidade. Esse resultado parece estar em consonância com o trágico quadro de crimes de ódio que ainda acontece no Brasil. Segundo o relatório de 2014 de Grupo Gay da Bahia sobre assassinato de LGBTs no país ${ }^{4}$ :

\begin{abstract}
O Brasil continua sendo o campeão mundial de crimes motivados pela homo/transfobia: segundo agências internacionais, 50\% dos assassinatos de transexuais no ano passado foram cometidos em nosso país. Dos 326 mortos, 163 eram gays, 134 travestis, 14 lésbicas, 3 bissexuais e 7 amantes de travestis (T-lovers). Foram igualmente assassinados 7 heterossexuais, por terem sido confundidos com gays ou por estarem em circunstâncias ou espaços homoeróticos (GRUPO GAY DA BAHIA, 2014, p.1).
\end{abstract}

Os dados são avassaladores. Na cidade do Rio de Janeiro ocorreu, em 2013, 1,22 mortes para cada milhão de habitantes. De certa forma, a denegação do direito de expressão de afetividade em lugares públicos a casais LGBT, como revelado pela pesquisa, funciona como uma espécie de aval para que aconteçam os crimes de ódio contra estes grupos. Curiosamente, a pesquisa se altera quando se fala em vida no espaço privado. Embora frágil, há uma maioria favorável à união de pessoas do mesmo sexo (a

4 Cf. https://homofobiamata.files.wordpress.com/2015/01/relatc3b3rio-2014s.pdf/ Acessado em 24/09/2016. 
pesquisa não perguntou “casamento”), 54\%, e a adoção por casais homoafetivos, 53\%. A sensação que este resultado produz é que a população do Rio de Janeiro está dizendo que aceita o estilo de vida LGBT desde que restrito ao espaço privado. Isso em muito se aproxima com a conhecida política norte americana do don't ask, don't tell por meio da qual se proibia tocar no assunto da homossexualidade nas forças armadas dos EUA. Essa mesma política foi usada como modelo para outras instituições e, a despeito de parecer um avanço na tolerância aos grupos LGBT, era, na verdade, a perpetuação do preconceito por colocar o tema da homoafetividade no lugar do tabu. Aqui cria-se uma situação ambígua: aceita-se o direito (legal), mas não se confere reconhecimento (moral). Já o inverso parece acontecer em relação às lutas pela igualdade racial. Vejamos os seguintes resultados assinalados no gráfico acima: $92 \%$ dos respondentes acreditam que as relações afetivas entre pessoas de raças diferentes devem ser garantidas como uma questão de direitos humanos, mas apenas $46 \%$ acreditam que devam ser reservadas cotas para negros e pardos em universidades públicas. É importante notar que não existe essa resistência em relação às cotas quando se fala de estudantes oriundos de escola pública e, principalmente, de pessoas com deficiência física. Ou seja, o problema não é com a proposta das cotas como forma de realização de políticas de ação afirmativa. O problema é em aplicar esse método a grupos afrodescendentes, ainda que estes grupos já tenham conquistado níveis mais elevados de respeito e consideração (embora ainda não o suficiente). Nesse caso parece haver a ambiguidade inversa em relação ao caso dos grupos LGBT: confere-se reconhecimento (moral), mas não se aceita o direito (legal). Trata-se de um conhecido discurso que afirma basicamente o seguinte: "ok você é igual a mim como ser humano, mas por isso mesmo não merece nenhum tratamento especial". Esse discurso encobre, erroneamente, o direito à diferença pela ideia de igualdade. Dessa forma, não consegue perceber que a igualdade de oportunidades exige tratar desigualmente os desiguais para, dessa forma, produzir mais igualdade com respeito às diferenças.

Ainda em relação à pauta da garantia de direitos civis e políticos dentro do movimento de luta pelo reconhecimento, gostaria de destacar mais duas respostas: $64 \%$ dos respondentes concordam que o uso de vagão exclusivo por mulheres em transportes 
públicos (trem, metrô) deve ser garantido como direito humano; e 73\% acham que também deve ser garantido como direito humano a demarcação de terras indígenas. Em relação a esta questão específica da demarcação de terras indígenas, é sabido que os maiores conflitos desta natureza estão nas regiões Norte e Centro-Oeste do Brasil, não obstante a presença de comunidades indígenas se dê por todo o território brasileiro. $\mathrm{O}$ estado do Rio de Janeiro conta com a presença de tribos indígenas, mas a luta por direitos dos índios não é algo claro e visível na cidade do Rio de Janeiro. Por isso mesmo, é difícil dizer se esta sensibilidade moral da população do Rio de Janeiro decorre apenas da comodidade de não precisar enfrentar este conflito no dia a dia da cidade. É bem verdade que no ano de 2013 houve um sério conflito em relação à questão indígena quando o então governador Sergio Cabral e o então prefeito Eduardo Paes decidiram, de comum acordo, pela derrubada do antigo Museu do Índio que fica no bairro do Maracanã para fazer no local um estacionamento e um centro comercial nos arredores do Estádio Maracanã. O Museu do Índio funcionou de 1910 a 1978, mas mesmo desativado o seu prédio acolhia, naquele ano, cerca de 150 índios. O local é conhecido como Aldeia Maracanã. Depois de muitos conflitos e enfrentamento com a polícia e autoridades públicas, a luta em favor da Aldeia Maracanã logrou-se vitoriosa e os governantes anunciaram publicamente a desistência da derrubada do prédio. Contudo, nenhuma política foi implantada, seja pela retomada do Museu, seja para o apoio aos índios que lá viviam. De toda sorte esse foi um raro exemplo de conflito indígena dentro da cidade do Rio de Janeiro. Considerando que a pesquisa foi realizada após o episódio, pode ser que a divulgação desse fato tenha estimulado a sensibilidade moral dos cariocas. De qualquer maneira, ainda que consideremos essa maciço apoio à demarcação das terras indígenas $(73 \%)$ como uma manifestação de caráter mais retórico, permanece como sendo positivo que essa enorme parcela da população do Rio de Janeiro reconheça as populações indígenas e, com isso, seu direito a autorrealização o que, por seu turno, implica o direito básico de manter suas terras tradicionais.

O outro ponto que destaquei foi o do direito ao vagão feminino. Se a questão indígena não é tão presente na cidade do Rio de Janeiro, o mesmo não se pode falar da questão da mulher. O Dossiê Mulher 2014 publicado pelo Instituto de Segurança Pública 
do Estado do Rio de Janeiro ${ }^{5}$ revela que a taxa de violência praticada contra a mulher permanece alarmante. $O$ quadro a seguir apresenta diferentes formas de violência caracterizadas a partir dos respectivos crimes (delitos) e apresenta o total geral de vítimas e, dentro deste, o total específico de vítimas do sexo feminino:

Tabela 2: Dados sobre a violência contra a Mulher no Estado do Rio de Janeiro Segundo Formas de Violência (2013)

\begin{tabular}{|c|c|c|c|c|}
\hline Formas de Violência & Delitos & Total de Vitimas & Vitimas Mulheres & $\begin{array}{c}\% \text { de Vitimas } \\
\text { Mulheres }\end{array}$ \\
\hline \multirow{3}{*}{ Violência Física } & Homicídio Doloso & 4.745 & 356 & $7,5 \%$ \\
\hline & Tentativa de Homicídio & 4.948 & 725 & $14,6 \%$ \\
\hline & Lesão Corporal Dolosa & 88.621 & 56.377 & $63,6 \%$ \\
\hline \multirow{2}{*}{ Violência Sexual } & Estupro & 5.885 & 4.871 & $82,8 \%$ \\
\hline & Tentativa de Estupro & 616 & 556 & $90,3 \%$ \\
\hline \multirow{3}{*}{ Violência Patrimonial } & Dano & 6.600 & 3.218 & $48,8 \%$ \\
\hline & Violação de Domicílio & 3.911 & 2.482 & $63,5 \%$ \\
\hline & Supressão de documento & 1.151 & 654 & $56,8 \%$ \\
\hline Violência Moral & $\begin{array}{c}\text { Calúnia/ Difamação/ } \\
\text { Injúria }\end{array}$ & 51.540 & 37.244 & $72,3 \%$ \\
\hline \multirow{2}{*}{ Violência Psicológica } & Ameaça & 83.689 & 55.218 & $65,9 \%$ \\
\hline & Constrangimento Ilegal & 1.578 & 941 & $59,6 \%$ \\
\hline
\end{tabular}

Fonte: DGTIT/PCERJ

Chama a atenção que os delitos que produzem um maior número de vítimas mulheres são exatamente os de natureza sexual (estupro e tentativa de estupro). Note-se que o objetivo do vagão exclusivo feminino é exatamente preservar a dignidade sexual da mulher diante de modos de abuso que banalizam a agressão sexual e abrem caminho para formas de violência mais dramáticas como a tentativa de estupro e o estupro, que no ano de 2013 vitimaram, ao menos, 5.427 mulheres no estado do Rio de Janeiro. ${ }^{6}$ Quando contrastamos o resultado da Pesquisa do Grupo DHPJS com estes dados do Instituto de Segurança Pública do Rio de Janeiro, temos que apesar de 64\% conformar uma ampla maioria a favor do vagão exclusivo, ainda assim esse número parece baixo diante das

\footnotetext{
5 http://arquivos.proderj.rj.gov.br/isp imagens/uploads/DossieMulher2014.pdf/ Acessado em $31 / 08 / 16$.

6 Disse "ao menos" porque o Dossiê têm como fonte o banco de dados dos Registros de Ocorrência (RO) das Delegacias de Polícia do estado do Rio de Janeiro, disponibilizado através do Departamento Geral de Tecnologia da Informação e Telecomunicações (DGTIT) da Polícia Civil. E todos sabemos que crimes em geral e especialmente aqueles contra a dignidade sexual são subnotificados.
} 
ameaças frequentes de violência, especialmente sexual, que pairam contra a mulher. Quais seriam as razões dos 36\% que são contrários ao vagão feminino? Aqui parece mais um caso onde o direito humano fica assegurado sem, contudo, haver um reconhecimento da dignidade moral das mulheres e do direito ao respeito que daí decorre. Nesse sentido, mais do que garantir direitos, é preciso fortalecer as lutas pela igualdade de gênero e promover políticas de educação a respeito do direito à diferença e à proteção especial.

Ainda em relação à tabela 1 , gostaria de destacar o tópico em que $73 \%$ dos respondentes afirmam que a reforma agrária é uma situação que deve ser garantida como direito humano. Esse ponto envolve diretamente uma questão de direito econômico e social e se insere dentro das lutas por redistribuição. A posse e a propriedade da terra no campo não se referem a uma questão básica de habitação, como é típico do movimento urbano dos sem teto. Elas tratam da questão do direito ao trabalho e à própria subsistência. Esse é, e sempre foi, a questão central do movimento dos sem terra. Por isso mesmo o MST se autodenomina Movimento dos Trabalhadores Rurais Sem Terra. De efeito, a questão da reforma agrária é, em última instância, a questão do trabalho e da renda para parcelas mais empobrecidas da sociedade. Admitir que o direito à terra e ao trabalho deve ser considerado um direito humano significa também admitir a humanidade daquele outro mais empobrecido que possui a mesma dignidade moral que eu. Claro que também aqui poderia ser arguido que a sensibilidade moral do carioca foi favorecida pelo fato de não haver conflitos agrários de grande intensidade na cidade do Rio de Janeiro. Aliás, talvez nem seja coincidência que igualmente $73 \%$ dos pesquisados tenham sido favoráveis tanto à demarcação das terras indígenas como à reforma agrária. Problemas mais rurais do que urbanos. Todavia, vale aqui o mesmo comentário que fiz em relação à demarcação das terras indígenas: ainda que consideremos esse maciço apoio à reforma agrária (73\%) como uma manifestação de caráter mais retórico, permanece como sendo positivo que essa enorme parcela da população do Rio de Janeiro seja a favor de políticas redistributivas e, com isso, ao direito econômico e social fundamental que é o acesso ao trabalho e à renda.

Passo a comentar agora alguns pontos da pesquisa que ensejam um interessante cruzamento entre direitos civis e políticos e luta por redistribuição: trata-se das questões 


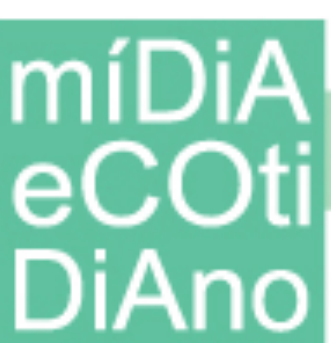

de segurança pública e ação policial. Minha hipótese é simples: o direito à segurança e integridade física está entre os mais elementares direitos civis e políticos e eles deveriam ser, supostamente, garantidos a todos os seres humanos numa sociedade democrática e formada por pessoas livres e iguais. Contudo, as graves contradições econômicas fazem que parcelas inteiras da sociedade sejam excluídas desse direito elementar à segurança e integridade física e, em alguns casos, do direito à vida. A literatura especializada possui várias análises acerca disso e uma das mais contundentes é aquela produzida por Giorgio Agamben, em especial em seu livro Homo Sacer: O Poder Soberano e a Vida Nua onde o autor explana sobre como o ocidente construiu a ideia da vida que não merece viver, da vida matável por ser considerada uma vida sem valor. Mas não pretendo explorar nesse artigo aspectos mais teóricos e sim fazer uma análise mais direta dos resultados da pesquisa.

Gráfico 1: Você considera a execução de preso algemado violação de direitos humanos? Sim: 89\% / Não: $11 \%$

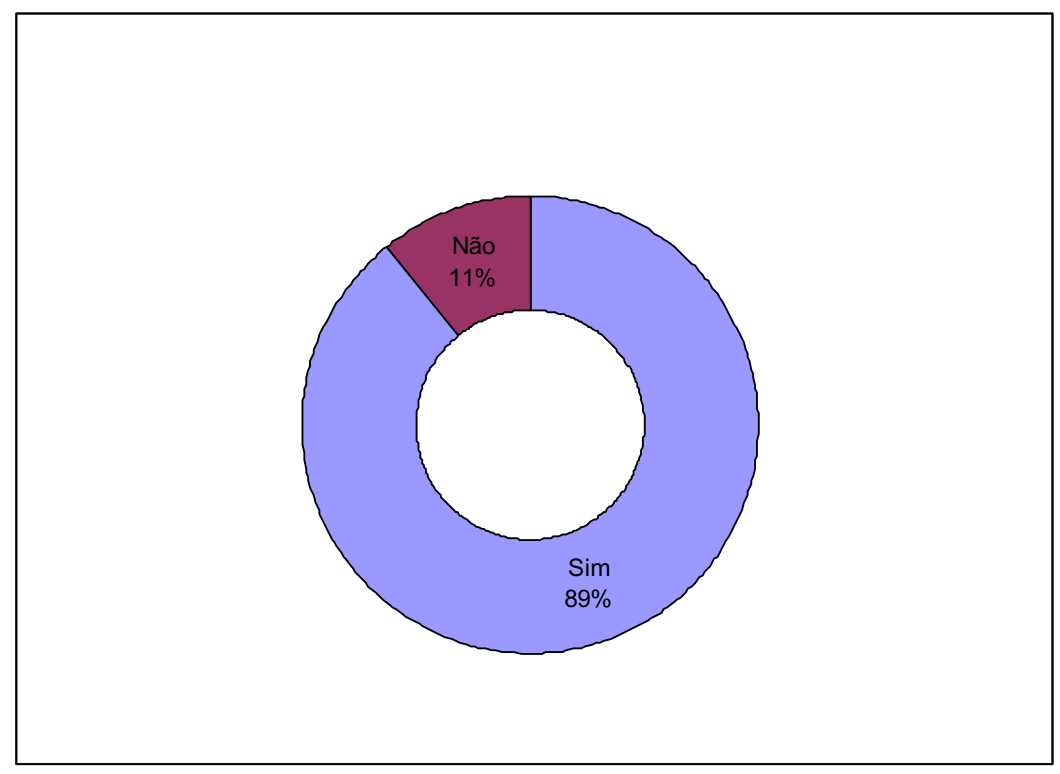

Aqui a sensibilidade moral do carioca parece estar bastante amadurecida. É aliviador saber que a maioria esmagadora dos respondentes (89\%) admite que a execução de preso algemado caracteriza uma violação de direitos humanos. Por outro lado é assustador imaginar que $11 \%$ ainda consideram que tal situação não seja uma violação de direitos humanos. É precisamente quanto a estes $11 \%$ que invoco a ideia de vida matável 
tal como explicada por Agamben. Mas aqui defendo a ideia de que existe um claro recorte de classe social. Não acredito que entre estas pessoas haja alguma que seja a favor de se executar um preso algemado que seja oriundo dos grupos mais abastados da sociedade. Aliás, embora haja cometimento de crimes em todas as classes sociais, não é comum se ver na rua ou na imprensa a figura de pessoas mais ricas e poderosas presas ou detidas com algemas. Meu ponto aqui é que as desigualdades econômicas e a falta de políticas redistributivas produzem também um esgarçamento de direitos civis e políticos e não apenas de direitos econômicos e sociais, mas, evidentemente, somente para as classes e grupos subalternizados da sociedade. Afirmo, sem medo de errar, que no imaginário dos $11 \%$ que admitem a execução de um preso algemado, este preso não aparece como uma pessoa distinta e elegantemente vestida, mas sim com aquele rompegalas que possui o conhecido estereótipo das chamadas "classes suspeitas".

Gráfico 2: Você considera agressão policial contra suspeito para ele confessar um crime de violação de direitos humanos? Sim: $85 \%$ / Não: 15\%

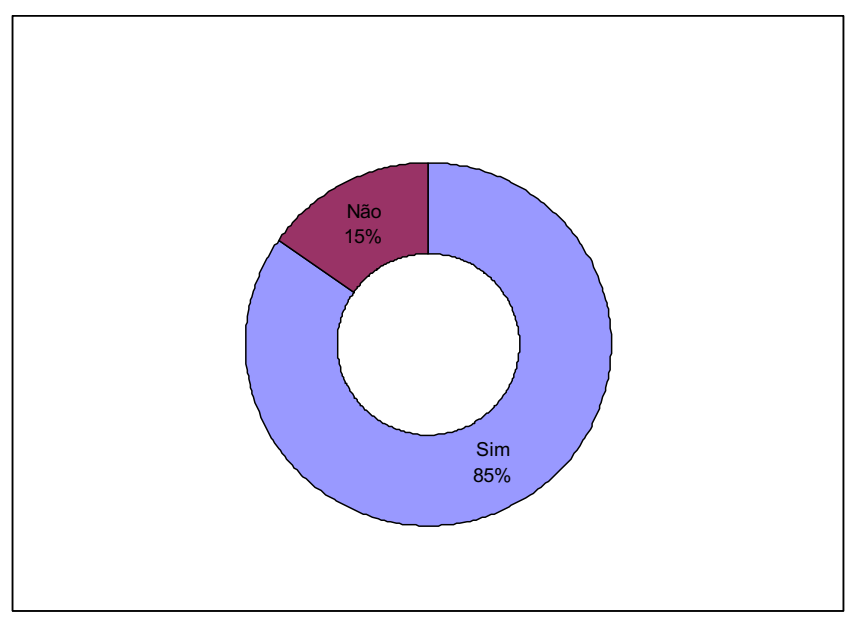

Continuando na mesma linha de análise é igualmente alvissareiro que $85 \%$ dos entrevistados considerem a agressão policial contra um suspeito para efeitos de confissão uma violação de direitos humanos. Se compararmos com o gráfico anterior há aqui uma ligeira titubeada da população uma vez que aumenta o grupo minoritário que não enxerga nesse tipo de ação policial uma violação de direitos humanos (15\%). É possível afirmar que desde a instituição da polis, o uso da força pelo poder soberano é uma máxima presente em todas as sociedades. Aliás, isso talvez seja mesmo uma primeira definição de 


\section{míDiA

política. A novidade no processo civilizatório é o advento da consciência moral e jurídica que coloca limites ao exercício do poder soberano. Isso é o que chamamos de direitos humanos. O mundo contemporâneo assistiu, após os atentados às torres gêmeas de Nova Iorque, uma série de teorias relativizando essa consciência moral e jurídica e admitindo que certos fins justifiquem o emprego de uma força ilimitada por parte do Estado. Mas o Brasil não é um país marcado por ataques terrorista e seria frágil afirmar que estas mesmas teorias estão inspirando os $15 \%$ que não se preocupam com a agressão policial para obtenção de confissão. Mas talvez eles estejam inspirados pela filosofia de que os fins justificam os meios. O problema é que ainda que queiramos seriamente levar tal filosofia em consideração, o fato é que a tortura não é um método eficiente de investigação pois a história desafortunadamente já nos mostrou que uma pessoa comum sob tortura é capaz de confessar qualquer coisa, o que fez e o que não fez. E todos sabemos que isso não é compatível com o princípio de busca da verdade real que deve presidir tanto a investigação criminal como o processo penal.

Gráfico 3: Você considera policial atirar em suspeito em fuga violação de direitos humanos? Sim: 68\% / Não: $35 \%$

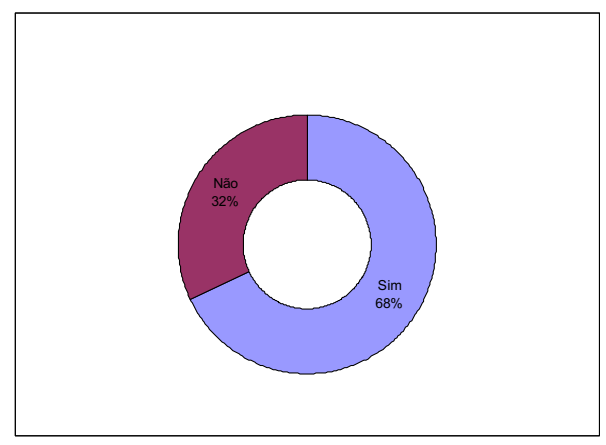

Aqui a fragilidade da consciência moral do carioca em relação ao direito à segurança e à integridade física (e, no limite, ao direito à vida) parece ter alcançado o seu maior nível. A boa notícia é que a grande maioria (68\%) ainda é contrária a esse tipo de situação por vislumbrar nela uma clara violação de direitos humanos. Mas 32\% aceitam tal hipótese, isto é, pessoas que não admitem a execução de presos algemados e a agressão policial para a obtenção de tortura já concordam que seja usada força letal contra um suspeito em fuga. Embora as convicções morais da maioria se mantenham em relação aos 
limites que devem ser colocados às ações das forças de segurança pública, as hipóteses apresentadas vão pouco a pouco minando essas convicções morais. Um interessante teste, o que poderia ser objeto de uma pesquisa futura, seria investigar a opinião das pessoas quanto à Lei No 9.614/98, também conhecida como lei do tiro de destruição de aeronaves. Essa Lei, e seu Decreto regulamentador, autoriza que aeronaves civis não identificadas e consideradas hostis sejam abatidas por caças militares brasileiros. Os que são favoráveis argumentam que é a única forma de diminuir o tráfico de entorpecentes no Brasil por evitar a entrada de drogas ilícitas por via aérea (normalmente aviões de pequeno porte que chegam carregados de drogas ilícitas de outros países e pousam no Brasil em pistas clandestinas). Muitas pessoas que são contrárias a que se atire num suspeito em fuga no solo admitem, como o faz a Lei 9.614/98, que se atire num suspeito em fuga se ele estiver pilotando uma aeronave. Minha intuição é que nessa hipótese da Lei do abate o número dos que não viriam nisso uma violação de direitos humanos aumentaria para além dos $32 \%$.

Outro aspecto positivo revelado pela pesquisa é que a mesma sensibilidade moral do carioca que vislumbra limites ao poder soberano do estado também está presente quanto à ação de particulares que procuram executar um suspeito sob a alegação de "justiçamento", o que, na verdade, não passa de linchamento. Isso é o que mostrou o fato de $74 \%$ dos respondentes considerarem que a prática de linchamento é uma violação de direitos humanos. Porém, mais impressionante do que a alvissareira marca dos $74 \%$ contrários, é o horror de saber que $26 \%$ dos entrevistados aceitam a prática dos linchamentos ou, ao menos, não consideram que isso seja uma violação de direitos humanos. A assim chamada "justiça com as próprias mãos" é um eloquente indicador de barbárie e déficit civilizacional. Nessas circunstâncias o suspeito é demonizado e como monstro ou bruxa lhe resta apenas a forca ou a fogueira. Claro que a comoção pública e o arrebatamento emocional que alguns crimes provocam são tão fortes que poderiam levar qualquer pessoa a uma situação limite como essa. Mas a pesquisa não foi feita com pessoas que praticaram linchamento e sim perguntou se o linchamento caracterizava ou não uma violação de direitos humanos; e $26 \%$ dos respondentes responderam racionalmente que não. Acentua-se que a pergunta completa fazia menção a linchamento 
de "batedores de carteira", o que é um delito que talvez sequer possa ser classificado de grave.

Gráfico 4: Você considera o recolhimento obrigatório de morador de rua violação de direitos humanos? Sim: 34\% / Não: $66 \%$

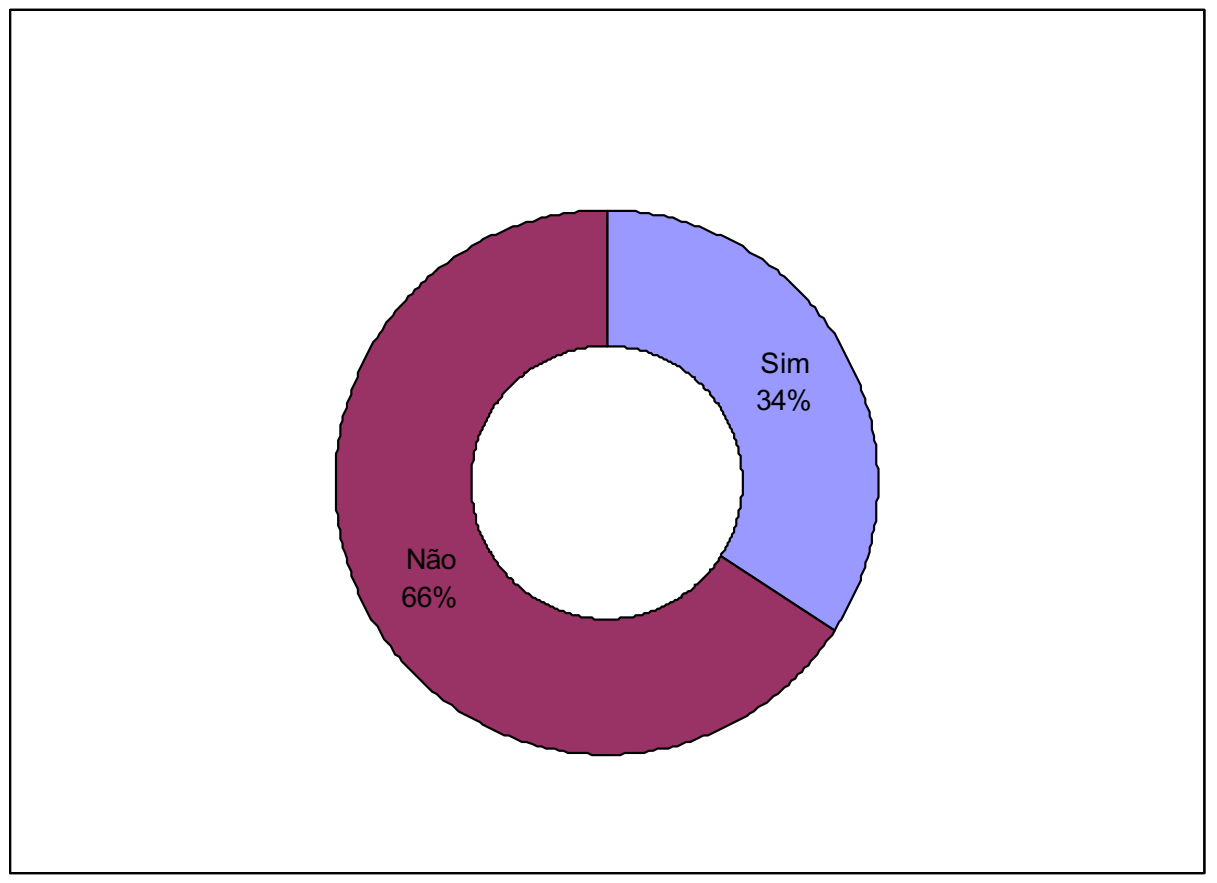

Quero começar reafirmando o que disse no parágrafo acerca da pergunta sobre execução de preso algemado: as desigualdades econômicas e a falta de políticas redistributivas produzem também um esgarçamento de direitos civis e políticos e não apenas de direitos econômicos e sociais, mas, evidentemente, apenas para as classes e grupos subalternizados da sociedade. Não há dúvida na literatura especializada, acerca do direito de ir, vir e permanecer como sendo um direito fundamental, inclusive assegurado pela Constituição brasileira, assim como pelas constituições em geral mundo afora. Contudo a sensibilidade moral do carioca não parece estar de acordo com isso uma vez que $66 \%$ dos respondentes consideram que recolhimento compulsório de morador de rua não é uma violação de direitos humanos. Evidentemente que poderia se tentar justificar esse posicionamento da grande maioria dizendo que ao responderem à pergunta tinham em mente políticas públicas de acolhimento por meio das quais se conduz o morador de rua para abrigos provisórios onde eles serão cuidados física e mentalmente e 
reencaminhados para as famílias ou colocados em albergues. Mas, sinceramente, não acredito nisso. Minha intuição é de que essa maioria de entrevistados não vislumbrou nessa situação (recolhimento compulsório) uma violação de direitos humanos simplesmente por não reconhecerem dignidade moral nas pessoas empobrecidas (ou que padecem de distúrbios psíquicos) que habitam as ruas. Certamente não há nada que incomode tanto a estética dos centros urbanos do que os moradores de rua. Mesmo em lugares como o Rio de Janeiro onde as favelas são expostas em função da topografia da cidade, esses aglomerados habitacionais mais precários não incomodam tanto como os moradores de rua. Na verdade as favelas cariocas foram incorporadas à vida e à cultura da cidade, às vezes com tanto romantismo que se esquece da precariedade de serviços públicos nestes locais, outras vezes com tanto preconceito que se fala nesses lugares apenas como lócus de violência real ou em potencial. Mas em ambas as situações há uma incorporação das favelas à vida da cidade. Porém, o mesmo não ocorre com a população de rua. Essa é sempre vista como ameaça à segurança e integridade dos demais ou, simplesmente, como uma degradação da estética urbana. Em qualquer caso, os moradores de rua parecem ser um estorvo que os coloca exatamente naquele lugar de vida que não merece ser vivida. Logicamente não se chega aqui ao limite da morte ou execução, o que provavelmente pareceria demasiado cruel até para as cabeças mais elitistas. Mas é muito conveniente que existam as políticas urbanas de recolhimento compulsório. Muitas vezes elas funcionam ao modo do pensamento de higienistas brasileiros do início do século XX que pregavam uma limpeza social e identificavam em certos grupos empobrecidos a consequência e também a causa de males e doenças. Nem é preciso lembrar como o higienismo flerta com o eugenismo. Voltamos ao conceito do exercício de um poder soberano sobre uma vida colocada em sua condição mais básica. É a própria corporeidade que está em jogo. O domínio do sujeito sobre o seu corpo desaparece pois esse é tomado como mero objeto do poder soberano que faz cessar o direito elementar de permanecer, instituindo assim uma exceção que se faz regra para todos aqueles que estão nessa situação. O desamparo da rua se torna, também, o desamparo do direito. E isso é confirmado pelo fato de $66 \%$ dos respondentes não perceberem o recolhimento compulsório como uma violação de direitos humanos. O empobrecimento e a falta de 
políticas redistributivas fazem desses moradores de rua pessoas abandonadas pelo direito (sem o direito de ir, vir e permanecer) que se convertem em um bando. E bandidas (desterradas, exiladas) da lei, passam a serem vistas como bandidos (malfeitor, criminoso) por boa parte da população.

\section{Considerações Finais}

O presente artigo procurou mostrar como a integração entre direitos humanos $\mathrm{e}$ cotidiano depende da compreensão acerca de quais são as convicções morais que uma dada população possui sobre questões recorrentes num dado espaço social; no caso concreto, a população da cidade do Rio de Janeiro. O cotidiano é aqui considerado não como aquilo que é comum ou banal, até porque os direitos humanos não possuem nada de banal, mas sim como uma certa maneira de ver o mundo e se relacionar com ele, onde vivências e percepções revelam o modo se ser e de pensar de um grupo. No caso dos direitos humanos, o cotidiano revela sentimentos morais que são decisivos na pretensão de constituição de uma sociedade democrática formada por pessoas livres e iguais.

Como chave de leitura teórica, para analisar e decodificar diferentes percepções das pessoas relativamente aos direitos humanos, utilizei a conhecida classificação desses direitos em duas grandes dimensões: os direitos civis e políticos, por um lado, e os direitos econômicos e sociais, por outro lado. Seguindo essa mesma linha, também considerei como chave de leitura, outra conceituação muito presente na filosofia política contemporânea: políticas de redistribuição e políticas de reconhecimento.

Na parte da pesquisa aqui apresentada e analisada, os entrevistados foram expostos, por meio do questionário, a uma série de situações do dia a dia da vida da cidade e precisaram se posicionar quando indagados se aquelas situações deveriam ser garantidas como direitos humanos ou não. O posicionamento dos entrevistados demonstrou que a ideia dos direitos humanos, para lá dos estereótipos e de falsas polêmicas muitas vezes levantadas por certos meios de mídias institucionais e sociais, parece estar consolidada no modo de pensar da população carioca. Mas isso não significa, como revelou a pesquisa, que essa mesma população sustente um tratamento linear, em termos de direitos humanos, a toda e qualquer pessoa, ao menos em certas situações do cotidiano. São algumas 
contradições dos sentimentos morais que revelam que ainda existe significativo preconceito em boa parte da população. Relembro aqui o representativo resultado de que 92\% dos respondentes consideraram que relação afetiva entre pessoas de raças diferentes deve ser uma situação protegida como um direito humano; porém, por outro lado, casal do mesmo sexo beijando em espaço público foi considerado uma situação que deve ser protegida como um direito humano por apenas $30 \%$ dos respondentes.

Outra parte da análise foi focada num campo que enseja um cruzamento entre direitos civis e políticos e luta por redistribuição: o campo da segurança pública e ação policial. Apresentei a hipótese de que o direito à segurança e integridade física está, teoricamente, entre os mais elementares direitos civis e políticos e eles deveriam ser, supostamente, garantidos a todos os seres humanos numa sociedade democrática. Contudo, as graves contradições econômicas fazem que parcelas inteiras da sociedade sejam excluídas desse direito elementar à segurança e integridade física e, em alguns casos, do direito à vida. Essa hipótese pode ser constatada em fatos concretos, especialmente no cotidiano das cidades grandes. Mas poderia também ser constatada na forma de pensar e nos sentimentos morais da população de uma dada cidade grande? A pesquisa revelou que em parte sim e em parte não. Para a felicidade daqueles que acreditam e defendem os direitos humanos, a maior parte foi não. Assim, práticas como a da execução de presos algemados e agressão policial para confissão de crime foram amplamente repudiadas como sendo violadoras dos direitos humanos. Claro que o percentual que disse aceitar essas práticas (de onze a quinze por cento), representa um número expressivo considerando que a cidade do Rio de Janeiro possui mais de seis milhões de habitantes, o que exige um constante sinal de alerta.

Em outra situação semelhante de cruzamento entre direitos civis e políticos e luta por redistribuição, o caso do recolhimento obrigatório de morador de rua, a hipótese acima foi constatada numa relação inversa. Isso porque $66 \%$ dos respondentes consideraram que o recolhimento compulsório dos moradores de rua não caracteriza uma violação de direitos humanos. O que faria uma parte majoritária e tão expressiva da população carioca simplesmente negar o direito de ir, vir e permanecer em logradouros públicos a certo grupo de pessoas? De acordo com a hipótese verificada, a resposta é uma 
e simples: a pobreza. Portanto, a não garantia de direitos econômicos e sociais acarreta um mal adicional que é a violação de direitos civis e políticos. Isso é algo que acontece no cotidiano das cidades e a maior parte da população parece admitir e concordar com isso. Em alguns casos, chega mesmo a desejar e cobrar essa prática dos governantes, como é a postura típica de parte da classe média que identifica naqueles mais empobrecidos uma ameaça.

Portanto, pode-se afirmar que a consolidação de uma cultura de garantia de direitos humanos para todos, no contexto de uma sociedade democrática de pessoas livres e iguais, ainda depende de ações políticas e institucionais, mas, também, de um movimento social que aumente a sensibilidade de todos para questões importantes de direitos humanos que acontecem no cotidiano e que promova sentimentos morais igualitários nas pessoas em geral.

\section{Referências}

AGAMBEM, Giorgio. Homo Sacer: o poder soberano e a vida nua I. Belo Horizonte: EdUFMG, 2004.

BOROWSKI, Martin. La estructura de los derechos fundamentales. Bogotá: Universidad Externado de Colombia, 2003.

COMPARATO, Fábio Konder. A Afirmação Histórica dos Direitos Humanos. São Paulo: Saraiva, 2007.

FRASER, Nancy. HONNETH, Axel. Redistribution or Recognition? A Political-Philosophical Exchange. New York: Verso, 2003.

FRASER, Nancy. Social Justice in the Age of Identity Politics: Redistribution, Recognition, and Participation. London: Essex University, 1999.

HONNETH, Axel. Luta por reconhecimento: a gramática moral dos conflitos sociais. São Paulo: Ed. 34, 2003.

NAGEL, Thomas. Poverty and Food: why charity is not enough. In POGGE, Thomas; MOELLENDORF, Darrel. Global Justice: seminal essays. Minneapolis: Paragon House, 2008.

POGGE. Thomas. Para Erradicar a Pobreza Sistêmica: em defesa de um dividendo dos recursos globais. SUR: Revista Internacional de Direitos Humanos. São Paulo, nº 6, ano 4, 2007.

SEN, Amartya. Desigualdade Reexaminada. Rio de Janeiro: Record, 2001.

Desenvolvimento como Liberdade. São Paulo: Cia das Letras, 2000.

SENGUPTA, Arjun. Poverty Eradication and human Rights. In: POGGE, Thomas. Freedom From Poverty as a Human Right: who owes what to the very poor? Oxford: Oxford University Press, 2007. 